\title{
A Brief Communication on a Cell Line of Neural Stem Cells B50 Cells Treated With a New Cisplatin-Based Drug
}

\author{
Ferrari $\mathrm{B}^{1}$, Astesana $\mathrm{V}^{1}$, De Pascali SA${ }^{2}$, Fanizzi FP ${ }^{2}$ and Bottone \\ $\mathrm{MG}^{1 *}$ \\ 1Dipartimento di Biologia e Biotecnologie "L. Spallanzani" Università di Pavia, via \\ Ferrata 9, 27100, Pavia, Italy \\ ${ }^{2}$ University of Salento, Di.S.Te.B.A., Campus Ecotekne, via Provle Lecce-Monteroni, \\ 73100, Lecce, Italy
}

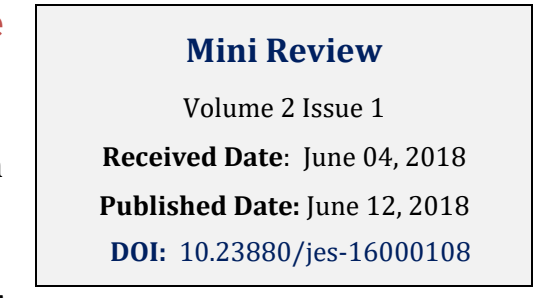

*Corresponding Author: Maria Grazia Bottone, Dipartimento di Biologia e Biotecnologie "L. Spallanzani" Università di Pavia, via Ferrata 9, 27100, Pavia, Italy, Tel: 0382986319; Email: mariagrazia.bottone@unipv.it

\section{Mini Review}

The B50 neuronal cell line was derived, in the 1974, from neuroblastoma in the neonatal rat central nervous system (CNS), and to date it's a cell line widely used in different studies. B50 cells offer several advantages to researchers for the study of CNS neurons in culture: they are simple to grow, to differentiate and to transfect. B50 cells have been extensively used in the study of death, toxicology and neuronal cell differentiation. Since 2008, Bottone and collaborators use this model to investigate the effects of cisplatin (cisPt) and new platinum compounds on the stem component of a brain tumour: neuroblastoma. Neuroblastoma is the most common extra-cranial solid tumour in infants and children and accounts for $8-10 \%$ of all childhood cancers. It causes the $15 \%$ of cancer deaths in the paediatric population. The incidence of neuroblastoma is 10.2 cases per million in children under 15 years of age and almost 500 new cases are reported each year [1].

Neuroblastoma can be seen as the result of a neural nature cell differentiation failure. The neural crest is a population of cells from neural folds and at the time of closure of the neural tube, these cells will be found in the dorsal part, but soon they will move away migrating in the surrounding tissues. The development of these crests is regulated by transcription factors Adam, et al. (2008) [2], post-transcriptional, post-translational modifications and epigenetic events [3].
The traditional treatment of neuroblastoma includes: chemotherapy, surgical resection and / or radiotherapy. However, many aggressive neuroblastomas have developed resistance to chemotherapeutic agents, increasing the probability of relapses. Induction chemotherapy is carried out by a combination of cyclophosphamide, doxorubicin, cisplatin, carboplatin, etoposide, topotecan, ifosfamide, and vincristine. The treatment does not exclude complications, because it can lead to growth disorders, endocrinopathies and the appearance of secondary malignancies [4].

[Pt $\left(0,0^{\prime}\right.$-acac $)(\gamma$-acac)(DMS)], called also PtAcacDMS, is a new platinum-based compound, that has shown less toxicity compared to cisPt. Indeed, during normal development of CNS, in rat cerebellum sections treated with the new compound, early minor apoptotic events was observed with a reduction in alteration of granule cell migration and in the growth of Purkinje cell dendrites [5]. Furthermore, PtAcacDMS enters in cells faster, about a quarter of more time than cisPt $[6,7]$.

Despite cisPt, PtAcacDMS target is not primarily DNA, in fact, it shows low reactivity with nucleobases and a specific reactivity with intracellular sulphur ligands. In rat neuroblastoma cells (B50), it has been observed that cisPt induces activation of the intrinsic apoptotic pathway, through the alteration of mitochondrial membrane 


\section{Journal of Embryology \& Stem Cell Research}

permeability [8]. Using immunocytochemical, cytometric and morphological techniques, it has also been shown that these compounds exert a cytostatic action and activate apoptosis by different pathways [9]. Morphological alterations of Golgi Apparatus, in B50 cells treated with cisPt, may be related to structural changes of the cytoskeletal system that is reflect in a strong production of vesicles and a spatial redistribution in dense masses [10]. After treatment with PtAcacDMS, an evident rearrangement has been detectable at the RE level: membranes completely disrupted and cisterns compressed into the cytoplasm without a uniform distribution was observed [9]. Recently, Grimaldi and collaborators (2016) have shown that the long-term effects of PtAcacDMS, exert cytotoxicity (induce cell death by apoptosis) in the neuronal B50 cell line but do not induce drug resistance. Furthermore, the alteration of the permeability of the external mitochondrial membrane induced by PtAcacDMS treatment causes the loss of the maintenance of $\mathrm{Ca}^{2+}$ and ATP homeostasis. The lack of this energetic molecule determines the blocking of the pumps responsible to the expulsion of $\mathrm{Ca}^{2+}$ from the cell, leading an increase in intracellular $\mathrm{Ca}^{2+}$ concentration. PtAcacDMS also causes the inhibition of $\mathrm{Ca}^{2+}$ transport pumps activity such as PMCA (Plasma Membrane Calcium ATPase), but not SERCA (Sarco/End plasmatic Reticulum Calcium ATPase) or SPCA (Secretary Pathway Calcium ATPase) and $\mathrm{Na}^{2+} / \mathrm{Ca}^{2+}$ pump. ROS production is also evident by inducing the activity of NAD (P) H oxidase, which directly induce DNA damage [11].

Based on these assumptions, we compared the effect of cisPt and PtAcacDMS treatment on intracellular calcium homeostasis in B50 cells. The presented data were obtained by fluorescent immunohistochemically and microscopic techniques. Images reported in (Figure 1) show immunolabelling for calcium-binding proteins Calmodulin (CaM) and Calretinin (CR). In eukaryotic cell, CaM has an important role in the regulation of several cellular functions. Interacting with many target protein, CaM controls cell proliferation and death processes i.e. apoptosis, autophagy and necroptosis $[12,13]$, regulating the physiology of cancer cells (including cancer stem cells) and the progression, growth, angiogenesis and metastases associated with the tumour. CR is a protein associated with development and regulates processes such as proliferation, differentiation and cell death. Moreover, even if still much discussed, it seems to be involved in neuro-protection.

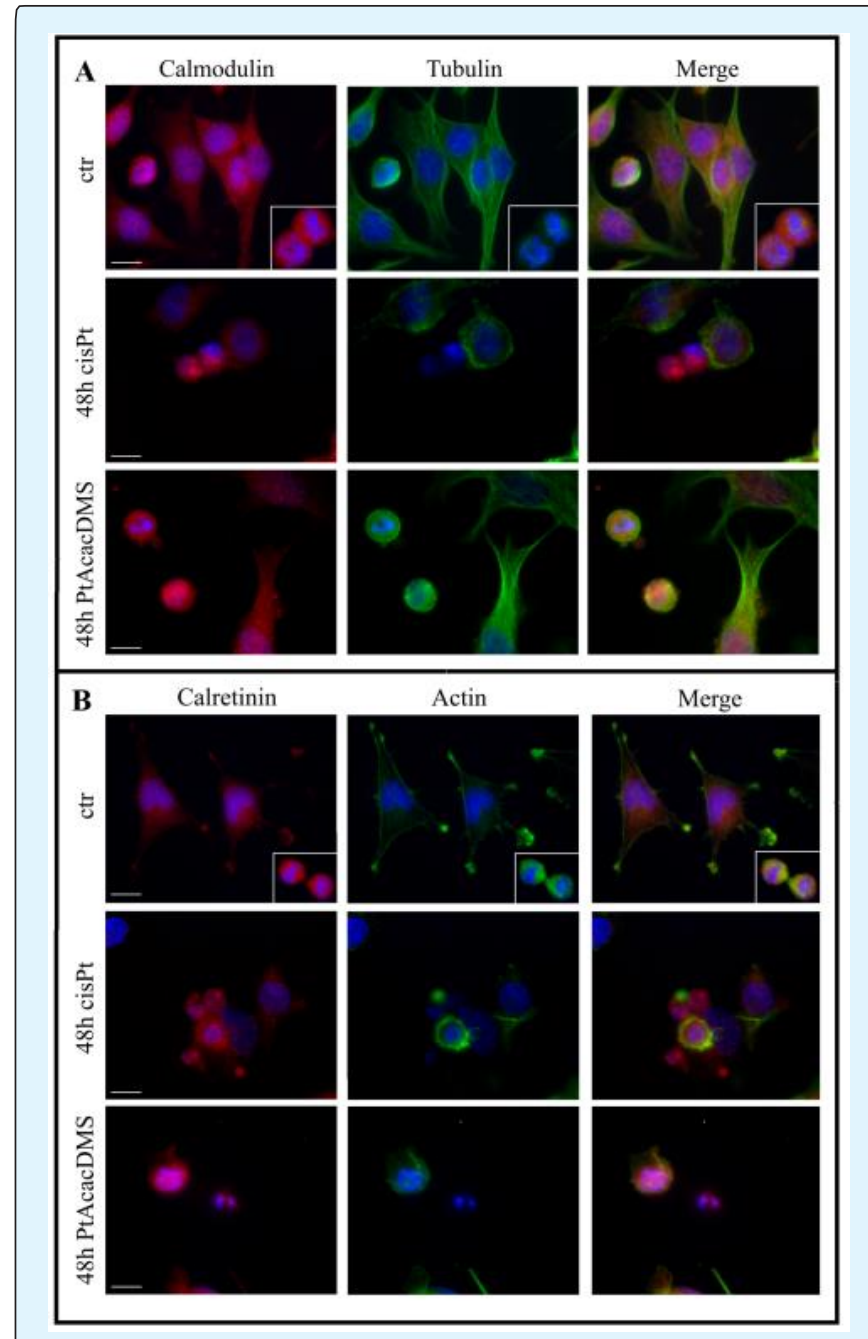

Figure 1: Double immunocytochemical detection in control (CTR) and in treated cells for $48 \mathrm{~h}$ at cisPt40 $\mu \mathrm{M}$ and PtacacDMS $10 \mu \mathrm{M}$ : (A) CaM(red fluorescence) and $\alpha$-Tubulin (green fluorescence); (B) CR (red fluorescence) and Actin (green fluorescence. DNA was counterstained with Hoechst 33258 (blue fluorescence). Bars: $20 \mu \mathrm{m}$.

This analysis was conducted on B50 neuroblastoma rat cells cultured in Dulbecco's Modified Eagle Medium (DMEM) supplemented with L-glutamine $(2 \mathrm{mM})$, penicillin $100 \mathrm{IU} \mathrm{ml}^{-1}$, streptomycin $\left(100 \mathrm{mg} \mathrm{l}^{-1}\right)$ and $10 \%$ fetal bovine serum (FBS). Cell culture was carried out at $37^{\circ} \mathrm{C}$ in a $5 \% \mathrm{CO}_{2}$ humidified chamber. 


\section{Journal of Embryology \& Stem Cell Research}

After treatment with cisPt $(40 \mu \mathrm{M})$ and PtAcacDMS $(10 \mu \mathrm{M})$ for $48 \mathrm{~h}$ at continuous exposure an immunohistochemistry detection for CaM and CR was performed, associated with a labelling for the tubulinic and actininc cytoskeleton respectively and a counterstained with Hoechst 33258for the nuclei (Table 1). For images acquisition an Olympus BX51 microscope equipped with a 100-W mercury lamp was used under the following conditions: 330-385 $\mathrm{nm}$ excitation filter (excf),
$400 \mathrm{~nm}$ dichroic mirror (dm) and $420 \mathrm{~nm}$ barrier filter (bf) for Hoechst 33258; 450-480 nm excf, $500 \mathrm{~nm}$ dm and $515 \mathrm{~nm}$ bf for the fluorescence of Alexa 488; $540 \mathrm{~nm}$ excf, $580 \mathrm{~nm} \mathrm{dm}$ and $620 \mathrm{~nm}$ bf for Alexa 594. Images were recorded with an Olympus MagniFire camera system and processed with the Olympus Cell F software. The analysis of the differences between the treated samples was conducted, evaluating three independent experiments for each condition and protein analysed.

\begin{tabular}{|c|c|c|c|c|}
\hline Antigen & Primary antibody & Dilution in PBS & Secondary antibody & Dilution in PBS \\
\hline Calmodulin & $\begin{array}{c}\text { Abcam, mouse monoclonal } \\
\text { IgG }_{1}\end{array}$ & $1: 200$ & Anti-mouse IgG1 Alexa Fluor 594 & $1: 200$ \\
\hline Calretinin & Swant, rabbit polyclonal & $1: 2000$ & Anti-mouse IgG1 Alexa Fluor 594 & $1: 200$ \\
\hline -Tubulin & $\begin{array}{c}\text { Invitrogen, mouse } \\
\text { monoclonal }\end{array}$ & $1: 100$ & Anti-mouse IgG1 Alexa Fluor 488 & $1: 200$ \\
\hline Actin & $\begin{array}{c}\text { Invitrogen, Alexa 488- } \\
\text { Phalloidin }\end{array}$ & $1: 40$ & & \\
\hline
\end{tabular}

Table 1: Primary and secondary antibodies used for immunocytochemical reactions at fluorescence microscope.

Images reported in (Figure 1) demonstrate that after treatment with PtAcacDMS and cisPt, there was an increase of red fluorescence relating to both CaM and CR respectively. A rearrangement of the actinic and tubulin cytoskeleton (green fluorescence) was observed compared to control sample. A clear intensification of CaM fluorescence was detectable in cells treated with PtAcacDMS compared to those treated with cisPt. This data is well correlated with the presence of a higher percentage of apoptotic cells obtained after PtAcacDMS treatment. Moreover, the increase of $\mathrm{Ca}^{2+}$ in cytosol correlates with mitochondrial alterations Grimaldi, et al. (2016) [7] which also induce higher ROS production and therefore an increase in oxidative stress [14].

These preliminary data, which will have to be confirmed by quantitative evaluations, appear promising and in line with others presented in the literature and give us the possibility to consider PtAcacDMS as a new strategy for tumours treatment, in particular by its action on pathways involved in CaM-dependent systems [15-19].

\section{References}

1. Park JR, Eggert A, Caron H (2008) Neuroblastoma: biology, prognosis, and treatment. Rev HematolOncolClin North Am 55(1): 97-120.

2. Adams M, Gammill L, Bronner-Fraser M (2008) Discovery of transcription factors and other candidate regulators of neural crest development. Dev Dynamics 237(4): 1021-1033.

3. Mayanil CS (2013) Transcriptional and epigenetic regulation of neural crest induction during neurulation. Dev Neurosci 35(5): 361-372.

4. Yalçin B, Kremer LC, Caron HN, van Dalen EC (2013) High-dose chemotherapy and autologous haematopoietic stem cell rescue for children with high-risk neuroblastoma. Cochrane Database Syst Rev (8): CD006301.

5. Bernocchi G, Bottone MG, Piccolini VM, Dal Bo V, Santin G, et al. (2011) Developing central nervous system and vulnerability to platinum compounds. Chemother Res Pract.

6. Muscella A, Calabriso N, De Pascali SA, Urso L, Ciccarese A, et al. (2007) platinum(II) complexes containing both an $0,0^{\prime}$-chelated acetylacetonate ligand and a sulfur ligand in the platinum coordination sphere induce apoptosis in HeLa cervical carcinoma cells. Biochem Pharmacol 74(1): 28-40.

7. Grimaldi M, Santin G, Insolia V, Dal Bo V, Piccolini VM, et al. (2016) $[\mathrm{Pt}(0,0$ '-acac) $(\gamma$-acac)(DMS)] versus cisplatin: apoptotic effects in B50 neuroblastoma cells. Histochem Cell Biol 145(5): 587-601. 


\section{Journal of Embryology \& Stem Cell Research}

8. Bottone MG, Soldani C, Veneroni P, Avella D, Pisu M, et al. (2008) Cell proliferation, apoptosis and mitochondrial damage in rat B50 neuronal cells after cisplatin treatment. Cell Prolife 41(3): 506-520.

9. Santin G, Piccolini VM, Veneroni P, Barni S, Bernocchi $G$, et al. (2011) Different patterns of apoptosis in response to cisplatin in B50 neuroblastoma rat cells. Histol Histopathol 26(7): 831-42.

10. Santin G, Scietti L, Veneroni P, Barni S, Bernocchi G, et al. (2012) Effects of Cisplatin in neuroblastoma rat cells: damage to cellular organelles. Int J Cell Biol 2012: 424072 .

11. Muscella A, Calabriso N, Vetrugno C, Fanizzi FP, De Pascali SA, et al. (2011) The platinum (II) complex $[\mathrm{Pt}(0,0$-acac $)(\gamma$-acac)(DMS)] alters the intracellular calcium homeostasis in MCF-7 breast cancer cells. BiochemPharmacol 81(1): 91-103.

12. Smaili SS, Quest AF, Hetz C, Lavandero S (2013) Editorial: signaling in cell death, survival, proliferation and degeneration. Curr Mol Med 13(2): 239-240.

13. Nomura M, Ueno A, Saga K, Fukuzawa M, Kaneda Y (2014) Accumulation of cytosolic calcium induces necroptotic cell death in human neuroblastoma. Cancer Res 74(4): 1056-1066.
14. Muscella A, Calabriso N, Vetrugno C, Fanizzi FP, De Pascali SA, et al. (2011) The signalling axis mediating neuronal apoptosis in response to $\left[\mathrm{Pt}\left(0,0^{\prime}-\mathrm{acac}\right)(\gamma\right.$ acac)(DMS)]. BiochemPharmacol 81(11): 1271-1285.

15. Berchtold MW, Villalobo A (2014) the many faces of calmodulin in cell proliferation, programmed cell death, autophagy, and cancer. Biochim Biophys Acta 1843(2): 398-435.

16. Cerri S, Piccolini VM, Santin G, Bottone MG, De Pascali SA, et al. (2011) The developmental neurotoxicity study of platinum compounds. Effects of cisplatin versus a novel Pt (II) complex on rat cerebellum. Neurotoxicol Teratol 33(2): 273-281.

17. De Pascali SA, Papadia P, Ciccarese A, Pacifico C, Fanizzi FP (2005) First examples of $\beta$-diketonate platinum (II) complexes with sulfoxide ligands. Eur J Inorg Chem 2005(4): 788-796.

18. De Pascali SA, Papadia $\mathrm{P}$, Capoccia S, Marchiò L, Lanfranchi M, et al. (2009) Hard/soft selectivity in ligand substitution reactions of beta-diketonate platinum(II) complexes. Dalton Trans (37): 77867795.

19. Kawai Y, Nakao T, Kunimura N, Kohda Y, Gemba M (2006) Relationship of intracellular calcium and oxygen radicals to cisplatin-related renal cell injury. J Pharmacol Sci 100(1): 65-72. 